\title{
Engine Oil Test Method Development
}

\author{
Máté ZÖLDY
}

\begin{abstract}
Climate change is an unavoidable global problem we must face sooner rather than later. Regulatory bodies are raising standards. One of these is for automotive manufacturers to decrease engine carbon-dioxide emissions, closely linked with fuel consumption, heavily influenced by the type of engine oil used. Engine bench tests are an accurate way to test the effectiveness of engine oils on fuel economy. This study aimed to develop a new method for engine oil testing in a moderate size, state-of-theart engine. Based on the literature overview, a test procedure was developed that was tested with three very different engine oils. Results confirm that with this new method, the differences between oil grades can be adequately measured and it is an efficient tool for further engine oil developments. It has the advantage that it needs a much lower amount of fuel than other test procedures and as a result, it is much easier to convert to current engines.
\end{abstract}

Keywords: carbon-dioxide emission reduction; engine oil development; method development

\section{INTRODUCTION}

Greenhouse gases (carbon dioxide, nitrousoxide, methane, chlorofluorocarbons and ozone) are far less commonly found in the atmosphere, although they are strongly anthropogenic, abrogating the climate of Earth [1]. The Paris Protocol in 2016, signed by more than 190 nations, was following the Kyoto Protocol to enhance this mainly carbon-based emission of industrialized nations of the world. The participants committed to keeping the average temperature increase of the Earth under $2^{\circ} \mathrm{C}$ based on the preindustralisation baseline. At 2020 environment and climate ministers of the European Union worked on the concrete steps needed to be taken so that the EU reaches its climate neutrality objective by 2050 . Air pollution remains the most important environmental cause of health problems in the EU in the next decades. The Council considered that established air quality standards, in particular limit values, have been effective and remain essential to protect the health of citizens. However, the Council stressed that there is room for improvements to the legislative framework to ensure good air quality across the EU [2]. The emission control technology for diesel engine exhausts should be improved not only in terms of fuel quality, internal combustion engine, and exhaust gas after-treatment technologies [3] but opportunities in engine oil management should be involved as well.

The aim of the European Union is that the fleet average carbon-dioxide emission of the automotive manufacturers be under $95 \mathrm{~g} / \mathrm{km}$ for 2021 and beyond. Therefore, automotive manufacturers do everything to reduce the carbon-dioxide emission of the internal combustion engine, which is related to fuel consumption. There is a direct correlation between a vehicle's fuel consumption and the $\mathrm{CO}_{2}$ emitted from that vehicle [4].

\section{LITERATURE REVIEW}

Fuel consumption of a vehicle depends, among other things, on the friction that must be overcome in the engine [5]. Clearly, this is influenced by engine design. Increasing oil change periods means that the oils have to work in a longer timeframe, and increasing demand from the engine side as downsizing causes higher expectations towards the engine oils [6]. However, friction in the engine can also be affected by lubricant viscosity. There are parts of the engine where due to boundary lubrication, the metal surfaces can touch and the use of surface active "friction modifier" additives can significantly reduce friction in these areas. Therefore, the requirement for an improved fuel economy has led to lower viscosity lubricants containing friction modifier additives. In 1990 the most common viscosity grade was SAE $15 \mathrm{~W}-40$. This is, on a global scale, probably still true today, although an increasing proportion of SAE $5 \mathrm{~W}-30$ and SAE $5 \mathrm{~W}-20$ grades is now available in the U.S. In Japan, most automotive manufacturers fill up new vehicles with SAE $0 \mathrm{~W}-20$ lubricants. In both these countries the ILSAC GF2, GF-3, GF-4 and GF-5 fuel economy engine test has been carried out on using lower viscosity grades lubricants. In Europe, since 1990 there has been a trend towards 0W (and $5 \mathrm{~W})$ grade lubricants, while at the same time having a 30 or 40 grade specification at high temperatures.

In terms of engine tests, the first U.S. fuel economy engine test was the Sequence VI. This used an engine with a sliding valve train system. Results showed that lower viscosity lubricants help lower fuel consumption, and the friction modifiers elevate its rate. Fuel economy improvement of candidate oils was evaluated against a 20W-30 ASTM HR reference oil.

This was followed by the Sequence VI-A test. This was used in ILSAC GF-2 [7], using a Ford 4.6 liter V8 gasoline engine. The engine had a roller follower valve train system (for the majority of the operation the contact was rolling, rather than sliding). The results showed that lower viscosity lubricants enable lower fuel consumption, and by the introduction of the roller follower valve train system, contrary to the previous test (with a sliding valve train system), engineers can be certain of minimal boundary friction in the engine, and so friction modifiers only had a small effect on fuel economy.

In the Sequence VI-B [8] test, the same engine was used for the Sequence VI-A test, but operating conditions were modified to increase the proportion of boundary friction (ASTM D 6837). For the Sequence VI-B test, the fuel economy of the test lubricant was evaluated under both "fresh" and "used" conditions (the Sequence VI-A test only measured the fuel economy benefit of fresh lubricant). The candidate oil was aged in the engine for 80 hours, which is equal to approximately $8000 \mathrm{~km}$ (which is typical of a U.S. 
oil drain interval). After aging, the fuel economy is measured again. The Sequence VI-B fuel economy engine test is used in both ILSAC GF-3 and GF-4 [9].

The VI-C method was designed but never implemented. In 2008 came the Sequence VI-D [10] fuel economy engine test, which was set out in place of Sequence VI-B, and an adaptable test for ILSAC GF-5. Both tests share the results proving the effect of viscosity grades and friction modifiers. The test engine is a 20083.6 L V6 General Motors gasoline engine, equipped with an external oil heating/cooling system, and a "flying flush" system is used for changing oils without an engine shutdown. The candidate oil is aged a sum-total of 100 hours. Fuel economy is measured after 16 hours and at the end. The results are evaluated against the base oil [11].

The "6.5 L Diesel Fuel Economy Improvement Test" was developed to measure the effects of engine oils on the fuel economy of diesel engines. This dynamometer test is used to measure the fuel efficiency performance of engine oils under conditions analogous to a typical driving cycle during operation of a $6.5 \mathrm{~L}$ diesel engine in a High Mobility Multipurpose Wheeled Vehicle. A 1994 GM 6.5 L diesel $\mathrm{V}-8$ 4-cycle engine is used as the test apparatus. The engine incorporates roller followers, two valves per cylinder, and mechanical fuel injection [12].

In Europe, the Mercedes Benz M111E [13] engine is used to assess the fuel economy improvement of an engine oil compared to a $15 \mathrm{~W}-40$ reference oil. The test duration is 24 hours, and a combined ECE-15 (4 cycles) + EUDC driving cycle is used. Engine speeds range from idle to $3071 \mathrm{rpm}$, and engine power from 0 to $49 \mathrm{~kW}$. Fluid temperatures range from 20 to $950{ }^{\circ} \mathrm{C}$ (coolant) and 20 to $1000{ }^{\circ} \mathrm{C}$ (oil) [14].

Table 1 Existing methods overview
\begin{tabular}{|l|c|c|c|c|c|}
\hline Name & standard & $\begin{array}{c}\text { year of } \\
\text { introduction }\end{array}$ & engine & cycle & aging time \\
\hline Sequence VIA & ASTM D 6202 & 1995 & Ford 4.6 1 V8 & EPA FTP-75 & $16 \mathrm{~h}$ \\
\hline Sequence VIB & ASTM D 6837 & 1998 & Ford 4.6 1 V8 & mod. EPA FTP-75 & $80 \mathrm{~h}$ \\
\hline Sequence VIC & none & 1998 & Ford 4.6 1 V8 & none & $120 \mathrm{~h}$ \\
\hline Sequence VID & ASTM D7589 & 2009 & Cadillac 3.6 1 V6 & $\begin{array}{c}\text { FTP-75, Highway } \\
\text { FE }\end{array}$ & $16 \mathrm{~h}+84 \mathrm{~h}$ \\
\hline $\begin{array}{c}\text { 6.5L Diesel } \\
\text { Fuel Economy } \\
\text { Improvement } \\
\text { Test }\end{array}$ & none & 1996 & $6.51 \mathrm{~V} 8$ & special & $16 \mathrm{~h}$ \\
\hline MB 111 & CEC-L-54-T-96 & 1996 & MB 2.0 l & ECE 15 + EUDC & $24 \mathrm{~h}$ \\
\hline
\end{tabular}

We reviewed engine oil fuel economy tests in large and older technology engines (Tab. 1). The aim of the process was to develop a new test procedure that is able to differentiate between engine oils in a state-of-the-art engine.

\section{METHODS AND EXPERIMENTAL}

Based on previous studies, the proposed test procedure has two main parts as well: A wear check analysis of the test oils to follow their internal changes and an engine test for simulating the aging of the engine with real conditions combined with fuel economy measurements.

\subsection{Measured Oil Wear Check Tests}

Wear-check oil analysis consists of a number of tests to monitor the rates of wear, contaminants, and additives in used oil. Contaminants include dirt, water, glycol, and fuel. It shows the mechanical condition of the component, and also determines the condition of the oil itself to help optimize drain periods.

Viscosity is defined as a measurement of resistance to flow and is a key physical property of lubricants. Engine oil viscosity is measured at $40{ }^{\circ} \mathrm{C}$ and $100{ }^{\circ} \mathrm{C}$. Viscosity is determined by measuring the time it takes for a liquid to flow between two sensors on a glass tube immersed in a constant temperature bath. The fluid is allowed to reach bath temperature before the analysis is performed.

Spectrographic metals analysis is usually the "heart" of most engine oil analysis programs. Using Inductively Coupled Plasma Spectrometer (ICP), 20 or more metals can be analysed simultaneously. With proper sample preparation, an ICP can measure in the 10's of parts per billion (ppb). The metals analysed include wear, additive, and contaminant metals and are reported in parts per million (ppm).

FT-IR analysis can qualify the amount of oxidation byproduct and nitration products present, qualify if glycol is present, and qualify if the water is present $>300 \mathrm{ppm}$.

\subsection{Engine Test Parameters}

During the last few decades, many fuel economy tests were developed, tracking the effect of different driving styles and customs. These tests smartly specify engine types, apparatus and operational parameters. If we do not hold one of the required engine types, we have to adopt the test for a new engine. First of all, the right test needs to be chosen. After considering different parameters (time the test was developed, driving styles in the countries under investigation), the Sequence VID test was chosen as a benchmark to measure the fuel economy. As in Europe, the common rail diesel engines are not only used in personal car segments but in light-duty vehicles as well, it was the chosen engine type. The test aimed to develop a new test method, facilitate the fuel economy test on the diesel engine from the perspective of the engine oil, and evaluate the results of a conventional test bench layout (Fig. 1).

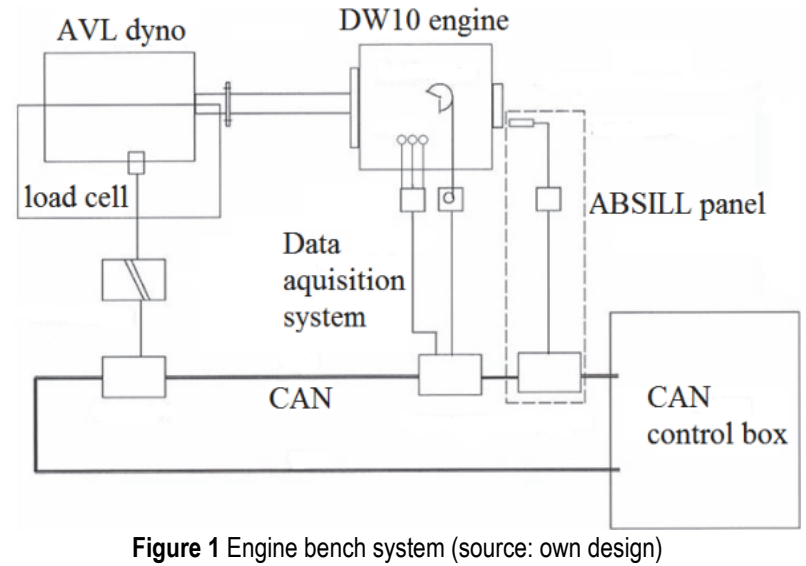

Three motor oils were chosen with significantly different characteristics to validate this test series. $15 \mathrm{~W}-40$ is a generally applied multi-grade engine oil (Oil A), the $5 \mathrm{~W}-30$ is a synthetic engine oil with high $(3.5 \mathrm{mPa} \mathrm{s})$ HTHS viscosity (Oil B), specially designed for extended oil change intervals. The third candidate $5 \mathrm{~W}-30$ is 
synthetic engine oil, engineered to improve fuel economy (Oil C) with an HTHS viscosity $3.2 \mathrm{mPas}$. All motor oils are put through a 106 hours test. First of all, the reference oil has to be sampled, and the test results are compared with the results of this reference oil. For this test validation the $15 \mathrm{~W}-40$ was chosen, which is reasonably the current engine oil in the world, and other tests (e.g.: CEC L-54-96) use this viscosity grade.

\begin{tabular}{|c|c|c|c|c|}
\hline \multicolumn{1}{|c|}{ Table 2 Test plan overview } \\
\hline Ref. oil & Baseline before 1 & $\begin{array}{c}\text { Time } \\
\text { required / h }\end{array}$ & $\begin{array}{c}\text { Time } \\
\text { passed / h }\end{array}$ & Comment \\
\hline Ref. oil & Baseline before 2 & 3 & & \\
\hline Test oil & Aging 1 & 16 & 16 & \\
\hline Test oil & $\begin{array}{c}\text { Fuel consumption } \\
\text { measuring }\end{array}$ & 3 & 19 & Sampling \\
\hline Test oil & Aging 2 & 42 & 61 & Sampling \\
\hline Test oil & Aging 2 & 42 & 103 & \\
\hline Test oil & $\begin{array}{c}\text { Fuel consumption } \\
\text { measuring }\end{array}$ & 3 & 106 & Sampling \\
\hline Ref. oil & Baseline after & 3 & & \\
\hline
\end{tabular}

The test was set up based on the international literature review. The first step is to fill the engine with the reference oil, and fuel consumption is measured twice at each of the four test conditions (Tab. 2 and Fig. 2)). The two baselines cannot differ by more than the measure of $+/-0.5 \%$ on every revolution.

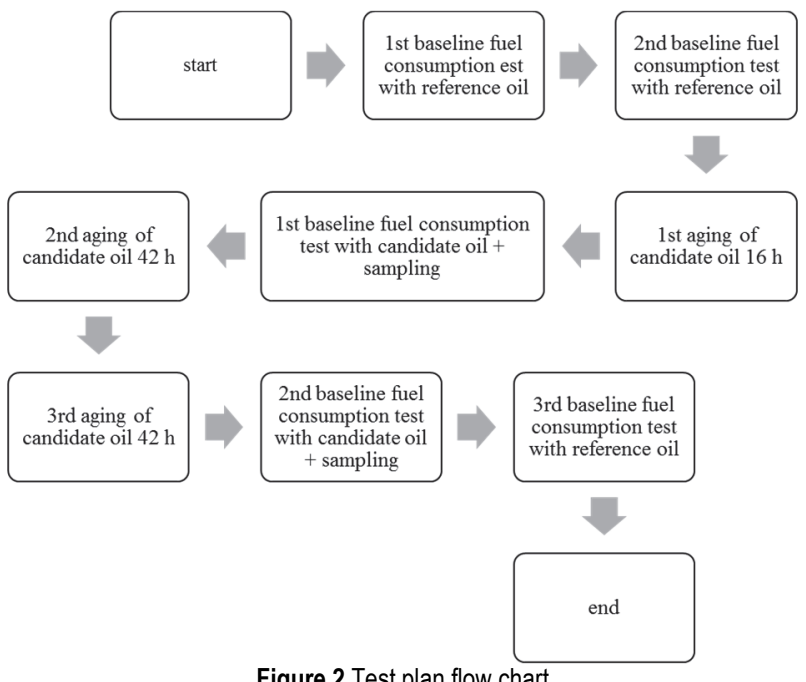

After this step, the candidate oil is introduced and aged for 16 hours at aging conditions (Tab. 3), and then fuel consumption is measured for each of the four test conditions. The candidate oil remains in the engine and is aged for 84 hours at aging conditions. Fuel consumption is measured for each of the four test conditions and followed by a repeat of the baseline oil at the four test conditions. The test is summarized in Tab. 2 .

Table 3 Aging parameters

\begin{tabular}{|c|c|}
\hline & Test conditions \\
\hline Rev $/ \mathrm{rpm}$ & 2100 \\
\hline Torque $/ \mathrm{Nm}$ & 125 \\
\hline Engine oil temp. $/{ }^{\circ} \mathrm{C}$ & 120 \\
\hline
\end{tabular}

The aging period was determined according to previous experiences with the chosen engine. The increased oil temperature was preferred to decrease the test time. Aging parameters are summarized in Table 3. Parameters were chosen based on previous outcomes on the test engine. Engine speed and torque combination is a full-throttle operation mode for the engine and engine oil temperature is increased by $20 \%$ to the normal values.

Table 4 Fuel consumption measuring

\begin{tabular}{|c|c|c|c|c|}
\hline Stage & 1 & 2 & 3 & 4 \\
\hline Rev / rpm & 1500 & 3000 & 2250 & 2750 \\
\hline Power / kW & 62 & 100 & 120 & 130 \\
\hline
\end{tabular}

Tab. 4. shows the fuel economy measurement data points. The main aspect of the determination of measurement point selection was to cover the main work area of the engine.

The test was accomplished with all three engine oils.

\subsection{Experimental}

A 2.0 common rail engine was chosen for the test. The 4-cylinder 2.0 L DW10 was the first PSA Diesel engine to feature common rail direct injection. It has a bore of $85 \mathrm{~mm}$ (3.3 in) and a stroke of $88 \mathrm{~mm}$ (3.5 in) for a total displacement of $1997 \mathrm{~cm}^{3}$, replacing the XUD9 in 1999. The DOHC 16-valve power plants were mated to a secondgeneration common rail injection system with a maximum injection system of 1600 bar (fitted with Euro 5 level fuel injection equipment) and a variable geometry turbocharger, pushing power to $165 \mathrm{~kW}$. Each injector has six holes of 110 microns $(0.11 \mathrm{~mm})$. The DW10 test was designed to simulate injector fouling with highly sensitive Euro 5 Siemens injector systems and measures power loss after 32 hours. Compared to the well understood CEC F23-01 XUD9 test method (which uses a much older indirect-injection engine), the new procedure represents a significant step up in severity. The bench was an AVL Alpha 160. This dynamometer is based on the eddy current principle. A standard Euro 5 diesel was used for the test with a FAME content of $4.4 \mathrm{vol} \%$. All tests were made with the same batch; there was not fuel quality during the measurements. Engine coolant was replaced before the test.

\section{RESULTS AND DISCUSSION}

Test oil parameters were measured after a $16 \mathrm{~h}, 58 \mathrm{~h}$ and $100 \mathrm{~h}$ run. This load simulates approximately 11000 $\mathrm{km}$ vehicle distance. During the oil quality measurements, kinematic and dynamic viscosity, fuel content, water and coolant content, oil conductivity index and soot and metal content were checked.

Kinematic viscosities of the samples were measured according to ASTM D 445 Standard Test Method for Kinematic Viscosity of Transparent and Opaque Liquids. It specifies a procedure for the determination of the kinematic viscosity of liquid petroleum products by measuring the time for a volume of liquid to flow under gravity through a calibrated glass capillary viscometer with an integrated thermometer. The dynamic viscosity can be 
obtained by multiplying the kinematic viscosity by the density of the liquid.

Viscosity changes are negligible during the $100 \mathrm{~h}$ engine bench load. Based on the fuel content measurement of the samples taken after $16 \mathrm{~h}, 58 \mathrm{~h}$ and $100 \mathrm{~h}$, it could be established that there was no fuel contamination as it is presented in Tab. 5 .

Table 5 Viscosity measurement results

\begin{tabular}{|c|c|c|c|}
\hline & $\begin{array}{c}\text { Sampling } \\
\text { time }\end{array}$ & $\begin{array}{c}\text { Kinematic viscosity } \\
\text { @ } 40^{\circ} \mathrm{C} / \mathrm{mm}^{2} / \mathrm{s}\end{array}$ & $\begin{array}{c}\text { Kinematic viscosity } \\
\text { a } 100^{\circ} \mathrm{C} / \mathrm{mm}^{2} / \mathrm{s}\end{array}$ \\
\hline \multirow{3}{*}{ Oil A } & $16 \mathrm{~h}$ & 99 & 13 \\
\cline { 2 - 4 } & $58 \mathrm{~h}$ & 98 & 12.9 \\
\cline { 2 - 4 } Oil B & $100 \mathrm{~h}$ & 98 & 13 \\
\cline { 2 - 4 } & $16 \mathrm{~h}$ & 72 & 11.6 \\
\cline { 2 - 4 } & $58 \mathrm{~h}$ & 72 & 11.7 \\
\hline \multirow{3}{*}{ Oil C } & $100 \mathrm{~h}$ & 73 & 11.7 \\
\cline { 2 - 4 } & $16 \mathrm{~h}$ & 59 & 10.5 \\
\cline { 2 - 4 } & $58 \mathrm{~h}$ & 60 & 10.4 \\
\hline
\end{tabular}

The oil conductivity index was measured according to in-house methods. Tab. 6 shows the measurement results. The conductivity index was decreased in all samples. The decrease ratio in all cases was between $0.7-0.77$. It means that the test affects the test oil's conductivity very similar.

Water content measurements do not determine any changes in the water amount of the samples during the aging process.

Table 6 Oil conductivity index results

\begin{tabular}{|c|c|c|}
\hline & Sampling time & Oil conductivity index (-) \\
\hline \multirow{3}{*}{ Oil A } & $16 \mathrm{~h}$ & 18 \\
\cline { 2 - 3 } & $58 \mathrm{~h}$ & 16 \\
\cline { 2 - 3 } & $100 \mathrm{~h}$ & 14 \\
\hline \multirow{3}{*}{ Oil B } & $16 \mathrm{~h}$ & 10 \\
\cline { 2 - 3 } & $58 \mathrm{~h}$ & 9 \\
\cline { 2 - 3 } & $100 \mathrm{~h}$ & 7 \\
\hline \multirow{3}{*}{ Oil C } & $16 \mathrm{~h}$ & 8 \\
\cline { 2 - 3 } & $58 \mathrm{~h}$ & 7 \\
\cline { 2 - 3 } & $100 \mathrm{~h}$ & 6 \\
\hline
\end{tabular}

The metal content of the engine oils was measured according to the test method for the determination of additive elements, wear metals and contaminants in used lubricating oils and determination of selected elements in base oils by inductively coupled plasma atomic emission spectrometer - ASTM D 5185-05 method. All the measured metal content was in the normal range [15] after $100 \mathrm{~h}$. A slight change was detectable at $\mathrm{Zn}$ and Fe content.

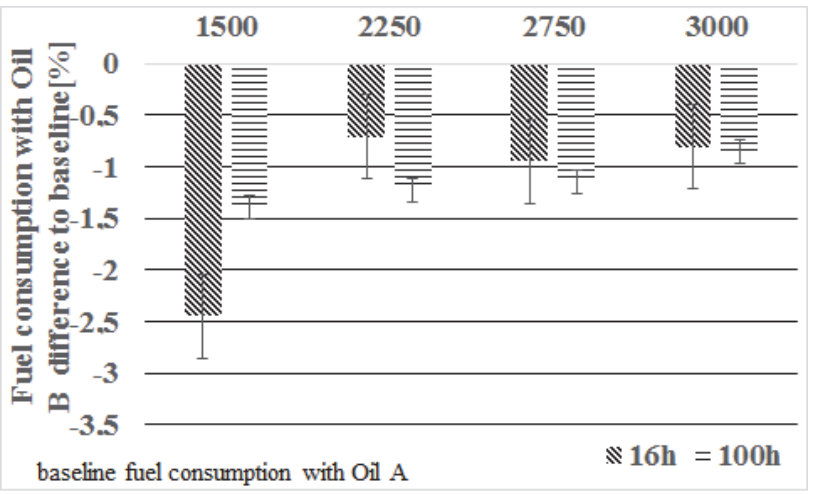

Figure 3 Oil B fuel economy effect

Fuel consumption measurements were carried out according to Tab. 2. A serial of 15 fuel economy test cycles was run and the results of the last 10 were averaged. Parameters of the fuel economy cycle are in Tab. 4. Figs. 2 and 3 show the fuel consumption difference from baseline in the case of HTHS viscosity engine oil used. Baseline fuel consumption is the measurement result of Oil A, $15 \mathrm{~W}$ 40 multi-grade engine oil.

Fig. 3. shows the increasing effect of Oil B fuel economy: test results after $16 \mathrm{~h}$ show $1.25 \%$ improvement in fuel economy as an average. After 100 hours of running on the bench indicates $0.88 \%$ average fuel economy improvement compared to the multi-grade engine oil.

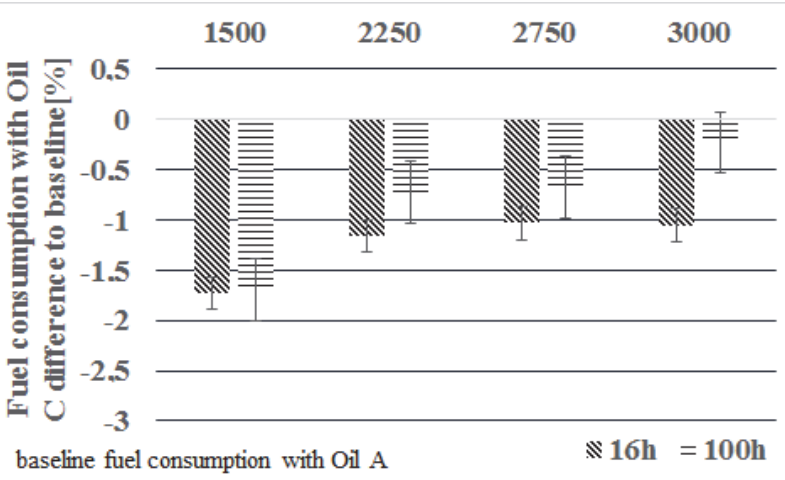

Figure 4 Oil $\mathrm{C}$ fuel economy effect

Fig 4. (5W-30) shows average fuel economy after 16 $(1.22 \%)$ and 100 hours $(1.20 \%)$.

A weighing table was utilized to accumulate the cycle point results to have an overall comparison between the tested fuels. The weight parameters are summarised in Tab. 7 , based on the rate of utilization of the measured points in the real driving conditions [16].

Table 7 Weight parameters

\begin{tabular}{|c|c|}
\hline Rev / rpm & Weighting /\% \\
\hline 1500 & 25 \\
\hline 2250 & 35 \\
\hline 2750 & 25 \\
\hline 3000 & 15 \\
\hline
\end{tabular}

Summarized, the results point to the possibility that the tests expected fuel economy difference between Oil B, Oil $\mathrm{C}$ and Oil $\mathrm{A}$ as reference were measurable. Oil B showed $0.88 \%$ fuel economy improvement after 100 hours, Oil C was $1.2 \%$ better.

Table 8 Fuel economy improvement / \%

\begin{tabular}{|c|c|c|}
\hline Motor oil & After 16 hours & After 100 hours \\
\hline Oil B & 1.25 & 0.88 \\
\hline Oil C & 1.22 & 1.20 \\
\hline
\end{tabular}

Compared to the presented methods, the benefit of the final procedure is that it uses an engine with actual technology. It guarantees that its results are aligned with the oils' effect in the passenger cars on the roads.

\section{CONCLUSIONS}

Aim of the research was, based on the literature overview of existing engine oil fuel economy tests, to develop a new test procedure on a state-of-the-art technology engine. A 2.0 litres common rail engine was chosen as test device and the parameters of a newly 
developed test method to measure engine oil effect on fuel economy were determined.

Validation tests showed that with the new method, the differences between oil grades can be measured. The main result of the research is a proven test cycle on a state-of-the art engine for validation of fuel economy effect of engine oils. The developed test procedure successfully proved that the differences between motor oils could be significant.

The suggested method showed that different motor oil additives cause substantial differences in fuel consumption, carbon footprint and physical properties. In the $21^{\text {st }}$ century all potential should be used for keeping carbon dioxide emission low. With the presented results, engine oils can be the part of carbon footprint reduction. It will be useful equipment and test procedure for further modern engine oil developments for additional fuel economy and carbon-dioxide emission decrease.

\section{REFERENCES}

[1] Zöldy, M. Investigation of Correlation Between Diesel Fuel Cold Operability and Standardized Cold Flow Properties, Periodica Polytechnica Transportation Engineering.

[2] European Green Deal. Retrieved from https://ec.europa.eu/info/publications/200114-european-green-deal-investmentplan_en

[3] Tan, J., Wei, Y., Sun, Y., Liu, J., Zhao, Z., Song, W., Li, J., \& Zhang, X. (2018). Simultaneous removal of NOx and soot particulates from diesel engine exhaust by 3DOM Fe-Mn oxide catalysts. Journal of Industrial and Engineering Chemistry, 63, 84-94. https://doi.org/10.1016/j.jiec.2018.02.002

[4] Szabó, Á. I., Schintzel, K., Dudás, A., \& Tóth-Nagy, C. (2016). Examination of the tribological behavior of nanotubular grapheme as additive in engine lubricant. 24th International Conference on Mechanical Engineering, 386389.

[5] Zöldy, M. (2020). Fuel Properties of Butanol - Hydrogenated Vegetable Oil Blends as a Diesel Extender Option for Internal Combustion Engines. Periodica Polytechnica: Chemical Engineering, 64(2), 205-212. https://doi.org/10.3311/PPch.14153

[6] Tóth, Á. D., Paulovics, L., Hanula, B., Knaup, J., \& Kopp, A. (2017). Methodenentwicklung zur Einstufung von Motorölen anhand tribologischer Eigenschaften.58. Tribologie-Fachtagung, P8-1-P8-11, 714.

[7] ASTM Int. (2002). Standard Test Method for Automotive Engine Oils on the Fuel Economy of Passenger Cars and Light-Duty Trucks in the Sequence VIA Spark Ignition Engine, (ASTM D6202-02) ASTM, West Conshohocken.

[8] ASTM Int. (2013). Standard test method for measurement of effects of automotive engine oils on fuel economy of passenger cars and light-duty trucks in sequence VIB spark ignition engine, (ASTMD 6837) ASTM, West Conshohocken.

[9] Taylor, R. I., Mainwaring, R., \& Mortier, R. M. (2005). Engine Lubricant Trends Since 1990. Chester, Shell Global Solutions. https://doi.org/10.1243/135065005X9718

[10] ASTM Int. (2016). Standard Test Method for Measurement of Effects of Automotive Engine Oils on Fuel Economy of Passenger Cars and Light-Duty Trucks in Sequence VID Spark Ignition Engine, (ASTMD7589) ASTM, West Conshohocken.

[11] Consortium to Develop a New Sequence VID Fuel Efficiency Test for Engine Oils - Final Report (2008). Retrieved from http://www.infineum.com/sitecollection documents/notebooks/gf5/ResearchReport.pdf

[12] Buscher, W. A. Worcester D: 6.5L Diesel Fuel Economy Improvement Test.
Retrieved from www.fueleconomytesting.swri.org

[13] CEC Quality Statement Disclaimer and Obligation (2008). CEC 11 ISSUE 6, CEC, 2008.

[14] ACEA European Oil Sequences. Retrieved from http://www.acea.be/images/uploads/files/2010_ACEAOil_Sequences.pdf

[15] $\bar{L}_{\text {imit }}$ values. Retrieved from https://en.oelcheck.com/wiki/Limit_values\#Typical_limit_values_for_m otor_oils

[16] Zöldy, M., Holló, A., \& Thernesz, A. (2012). Development of More Efficient Fuels for Niche Markets. Proceedings of the FISITA 2012: Advanced Internal Combustion Engines.

\section{LIST OF ABBREVATIONS}

\begin{tabular}{|c|c|}
\hline ASTM & $\begin{array}{l}\text { American Society for Testing and } \\
\text { Materials }\end{array}$ \\
\hline ASTM HR & $\begin{array}{l}\text { American Society for Testing and } \\
\text { Materials High Reference (oil) }\end{array}$ \\
\hline $\mathrm{CAN}$ & - Controller Area Network \\
\hline $\mathrm{CEC}$ & - Coordinating European Council \\
\hline $\mathrm{CO} 2$ & - carbon dioxide \\
\hline $\mathrm{DOHC}$ & - Double Overhead Camshaft \\
\hline DW10 & - engine code of Peugeot \\
\hline EU & - European Union \\
\hline EUDC & - Extra Urban Driving Cycle \\
\hline FAME & - Fatty-acid-methyl-ether \\
\hline HTHS viscosity & - High Temperature High Share viscosity \\
\hline $\mathrm{ICP}$ & - Coupled Plasma Spectrometer \\
\hline ILSAC & $\begin{array}{l}\text { - International Lubricants Standardization } \\
\text { and Approval Committee }\end{array}$ \\
\hline SAE & - Society of American Engineers \\
\hline XUD9 & - Engine code of Peugeot \\
\hline
\end{tabular}

\section{Contact information:}

Máté ZÖLDY, PhD, Senior Research Fellow (Corresponding author)

BME - Budapest University of Technology and Economics H 1111 Budapest Stoczekutca 6, Hungary

E-mail: mate.zoldy@auto.bme.hu 